\title{
Escrita acadêmica de qualidade: compreendendo 0 gênero textual, aprende-se a escrever
}

\author{
Ricardo Eugenio Dill \\ Biólogo e Tecnólogo em Agroindústria. Unidade de Cruz Alta, Universidade \\ Estadual do Rio Grande do Sul, Cruz Alta, RS, Brasil \\ E-mail: ricardo-dill@uergs.edu.com \\ Doutora em Letras: Estudos Linguísticos - UFSM. Professora Adjunta da \\ Universidade Estadual do Rio Grande do Sul - Unidade em Cruz Alta. \\ Dioni Maria dos Santos Paz \\ E-mail: dioni-paz@uergs.edu.br \\ Recebido em: 13 abril 2018. Aceito: 12 maio 2018. \\ DOI: http://dx.doi.org/10.21674/2448-0479.43.478-486
}

\section{Resumo}

A linguagem é a aptidão dos humanos que permite a capacidade de expressar algo, manifestar opiniões e desejos, assim como a troca de informações. A escrita e a oralidade são as formas mais amplas e eficientes para tais objetivos, no entanto elas seguem estruturas para a organização de ideias, através de gêneros textuais bem característicos. Na academia temos padrões de textos específicos. Esses padrões textuais, muitas vezes, são impedimentos aos acadêmicos novatos, em decorrência da falta de familiaridade e da ausência de uma direção sobre quais instrumentos utilizar. Observando essas adversidades, ofereceu-se o Curso de Inverno: Redação Científico/Acadêmica (des)complicada e formas de divulgação no recesso de inverno da UERGS. Realizaram-se discussões sobre as normas para elaboração de gêneros de textos como resumos acadêmicos, resenhas críticas, artigos científicos, comunicação oral e pôster científico. O objetivo foi guiar os acadêmicos em atividades de leitura, de produção e de exposição de conteúdo. O curso teve duração de 30 horas, com um total de 15 participantes concluintes. A dinâmica do curso envolveu atividades expositivas, práticas de elaboração do gênero resumo acadêmico, de 250 palavras, e uma resenha crítica. Os alunos também criaram uma apresentação padrão de tema livre para realizar uma comunicação oral no último dia do curso. Ao final do curso pôde-se observar nos participantes uma evolução do conhecimento sobre as estruturas que compõe cada forma acadêmica de escrita ou divulgação. Para muitos a barreira de não saber como fazer foi desfeita, restando agora iniciar a escrever as suas futuras publicações.

Palavras-chave: Curso de Férias. Gêneros de textos. Redação Acadêmica. 


\section{Abstract \\ Qualitity academic writing: understanding the textual genre, o learns to write}

The language is the aptitude of humans that allows the ability to express something, express opinions and desires, as well as the exchange of information. Writing and orality are the most ample and efficient forms for such objectives, but they follow structures for the organization of ideas, through wellcharacterized textual genres. At the university, we have specific text standards. These textual standards, many times, are impediments to the novice academic, due to the lack of familiarity and the absence of a direction on which instruments to use. Observing these adversities, the Winter Course offered: Scientific / Academic Writing (dis) complicated and forms of dissemination in the winter recess of the UERGS. Discussions were held on the norms for the elaboration of genres of texts such as academic summaries, critical reviews, scientific articles, oral communication and scientific poster. The objective was to guide students in reading, production and content exposure activities. The course lasted 30 hours, with a total of 15 participants. The dynamics of the course involved expository activities, elaboration practices of the academic abstract genre, of 250 words, and a critical review. Students also created a standard free-form presentation for oral communication on the last day of the course. At the end of the course it was possible to observe in the participants an evolution of the knowledge about the structures that make up each academic form of writing or divulgation. For many, the barrier of not knowing how to do it was undone, and now they are beginning to write their future publications.

Keywords: Extension. Holiday Course. Scientific Writing.

\section{Introdução}

O ensino e a aprendizagem de produção de textos, desde muito tempo, representam um grande dilema para professores e alunos. Essa realidade insere-se num contexto que apresenta várias lacunas, oriundas de vários fatores. Vale sublinhar que duas das principais causas do problema são o desconhecimento de técnicas de redigir e o desconhecimento das estruturas que fazem parte dos diferentes gêneros de textos (PAZ, 2006).

Para dirimir tais dificuldades, fundamentamos nosso trabalho de ensinar a ler e a produzir textos na teoria dos gêneros textuais. Tais gêneros fazem parte do nosso cotidiano em casa, na universidade, na escola, na rua, no cinema, no teatro, no rádio ou na televisão. Aquele que comunica o faz através de um gênero específico: resumo, resenha, artigo, fábula, conto, romance, ata, receita, relatório, publicidade, poema e tantos outros gêneros textuais escritos ou orais. Sendo assim, em toda atividade social da linguagem, estão imbricados os gêneros textuais, que estarão sempre em transformação e sujeitos às avaliações por parte da sociedade porque servem de modelos para as 
ações da linguagem. Estes textos são organizados em vários e diferentes padrões de manifestações da linguagem conforme situações ou necessidades dos sujeitos.

Bakhtin (2006, p. 261), em "Estética da Criação Verbal", dedica um capítulo sobre a heterogeneidade dos gêneros do discurso e argumenta que "todos os diversos campos da atividade humana estão ligados ao uso da linguagem". Na reflexão bakhtiniana, os gêneros discursivos referem-se ao funcionamento da língua em práticas comunicativas praticadas por sujeitos que interagem na sociedade e no meio em que vivem. Consequentemente, os gêneros são excelentes instrumentos para promover a comunicação, a reflexão e a aprendizagem entre os envolvidos.

O autor acrescenta que:

\begin{abstract}
A riqueza e a diversidade dos gêneros do discurso são infinitas porque são inesgotáveis as possibilidades da multiforme atividade humana e porque em cada campo dessa atividade é integral o repertório de gêneros do discurso, que cresce e se diferencia à medida que se desenvolve e se complexifica um determinado campo (BAKHTIN, 2006, p. 262).
\end{abstract}

Nessa perspectiva, a linguagem é a aptidão desenvolvida pelos humanos que permite a capacidade de expressar algo. É das particularidades que mais distinguem a espécie humana, permitindo atribuir significado ao utilizar símbolos, formas, imagens e sons que seus iguais possam compreender. Dessa forma, a linguagem toma função social própria entre os adeptos de uma mesma língua: ler, escrever, falar e escutar.

Em se tratando de gêneros de textos, o trabalho na academia tem a ver com o saber, utilizando, basicamente, as palavras (LARROSA, 2003). Gastamos grande parte do nosso tempo de trabalho lendo e escrevendo. Não lemos e escrevemos, necessariamente, porque gostamos, mas porque trabalhamos lendo e escrevendo; isso faz parte do nosso contrato de trabalho, e, hoje, cada vez mais temos que prestar contas, em números, das nossas atividades que se expressam por meio de relatórios, projetos, artigos, livros, trabalhos em anais de congressos, etc. (MARINHO, 2010). Larrosa, em seu ensaio, esclarece-nos que mesmo que os textos sejam o nosso principal instrumento na academia, ainda estamos longe de dominar o que é de fato a escrita:

\footnotetext{
Parece-me sintomático que no território acadêmico se problematize o método e não a escrita. A imagem dogmática do conhecimento e do pensamento oculta que o que fazemos na maior parte do tempo é ler e escrever. E oculta, supondo que já sabemos ler e escrever que: ler não é senão compreender o pensamento, as ideias, o conteúdo ou a informação que há no texto, e escrever não é senão esclarecer o que já se havia pensado ou averiguado, ou seja, o que já se pensa e se sabe (LARROSA, 2003, p.108).
}

Ao fim dos anos 90, estabeleceu-se a crença de que os acadêmicos que ingressavam na universidade dominavam alguns gêneros do discurso e que o ensino dos gêneros acadêmicos deveria acontecer em situações de escrita no interior das diferentes disciplinas do currículo (FIAD, 2011). Porém, na academia temos padrões de textos específicos. Esses padrões textuais, muitas vezes, são barreiras aos acadêmicos, em decorrência da inexistente da familiaridade com o gênero e da ausência do direcionamento sobre quais instrumentos utilizar. 
Para muitos dos docentes universitários, causa estranhamento o fato de deparar com alunos pouco familiarizados com a leitura e a produção de gêneros que apoiam as suas aulas e eventos próprios da vida acadêmica. Porém, é de conhecimento comum, que gêneros linguísticos acadêmicos não constituem conteúdo e nem práticas nas escolas de ensino fundamental e médio (MARINHO, 2010), em nosso país. A autora reitera que a leitura e a escrita de gêneros de referência na academia como artigos, teses, monografias, dissertações, resenhas acadêmicas, entre outros, são realizadas preferencialmente na universidade, pois é nessa esfera que são produzidos esses gêneros, logo, podemos dizer que é esse o local onde devem ser discutidos e ensinados.

No entanto, a universidade acreditou que as suas convenções que regulam a escrita acadêmica seriam transparentes o suficiente para quem faz parte da comunidade acadêmica e aqueles que almejam entrar nela. Mas o que é observado é justamente o contrário, as convenções da escrita que circulam na esfera acadêmica não são tão transparentes assim e muito menos explicitadas ao aluno. A realidade, é que há uma negação do educando real com o qual o professor está interagindo, ao não reconhecê-lo como é, há a negação da voz do aluno no processo de ensino-aprendizagem e há a negação ao estudante das convenções que regem a escrita acadêmica (FIAD, 2011).

As observações realizadas por Marinho (2010) e Fiad (2011) comprovam que a dificuldade primordial dos universitários é compreender as concepções e expectativas dos seus professores quando são demandadas tarefas de leitura e, principalmente, de produção de textos. O que está ocorrendo é que, muitas vezes, o professor não costuma explicitar de forma suficiente o que está sendo solicitado. Consequentemente, ocorre uma ausência do engajamento das práticas linguísticas esperadas no contexto acadêmico. Felizmente, esse cenário está mudando, pois estudos e pesquisas mostram que é necessário cuidar desse objeto de ensino, uma vez que esse investimento propiciará um ganho de conhecimento e qualidade de aprendizagem aos alunos.

Observando essas adversidades encontradas no cerne do meio acadêmico, foi ofertado o Curso de Inverno - Redação Científico/Acadêmica (des)complicada e formas de divulgação no recesso de inverno da Universidade Estadual do Rio Grande do Sul. Com o objetivo foi proporcionar um tempoespaço de prática dos gêneros textuais para que os jovens acadêmicos ingressantes que acreditavam ter dificuldades em atividades de leitura, de redação e de exposição de conteúdos desenvolvidos pela academia, adquirissem conhecimentos específicos sobre leitura e produção de textos acadêmicos. Este artigo apresenta o relato das atividades desenvolvidas no curso de extensão: Curso de Inverno - Redação Científico/Acadêmica (des)complicada e formas de divulgação.

\section{Material e Métodos}

\section{Período e local}

O desenvolvimento das atividades do Curso de Inverno ocorreu durante a semana do final do mês de julho de 2016, num total de seis dias contabilizando 30 horas de atividades, nas dependências da Universidade Estadual do Rio Grande do Sul na Unidade Universitária em Cruz Alta. 
Os participantes fizeram uso do laboratório de informática para produzir os seus textos e apresentações.

\section{Público alvo}

Estiveram presentes acadêmicos dos cursos de graduação em Licenciatura em Pedagogia e de Bacharel em Ciência e Tecnologia de Alimentos da UERGS.

\section{Instrumentos de aprendizagem}

As atividades do curso foram desenvolvidas, primeiramente, através de aulas expositivas. Durante as aulas os alunos fizeram o uso de textos que exemplificavam cada gênero textual. Com eles realizou-se a leitura e a análise estrutural do conteúdo do texto: "A normose acadêmica" (SOUZA, 2014). Este serviu de base para praticar a elaboração do resumo e da resenha crítica pelos participantes conforme o demostrado em aula.

\section{Desenvolvimento do curso}

A dinâmica das atividades do curso ocorreu para possibilitar que os participantes tivessem contato com os gêneros textuais acadêmico/científicos, através da observação e identificação das estruturas que compõem cada gênero. Os conteúdos foram desenvolvidos conforme é observado no cronograma do quadro 1.

Quadro 1: Cronograma de atividades propostas do curso.

\begin{tabular}{|c|c|c|}
\hline & Gênero textual & Extraclasse \\
\hline Primeiro dia & $\begin{array}{l}\text { Importância das normatizações; } \\
\text { Apresentação dos principais gêneros } \\
\text { acadêmicos; } \\
\text { Análise da estrutura de Resumos. }\end{array}$ & Elaboração de resumo simples de um texto. \\
\hline Segundo dia & $\begin{array}{l}\text { Apresentação e análise da estrutura da } \\
\text { Comunicação Oral. }\end{array}$ & $\begin{array}{l}\text { Elaboração de uma apresentação para } \\
\text { comunicação oral. }\end{array}$ \\
\hline Terceiro dia & $\begin{array}{l}\text { Análise da estrutura de Resenha } \\
\text { Crítica. }\end{array}$ & Elaboração de uma resenha crítica de um texto \\
\hline Quarto dia & $\begin{array}{l}\text { Leitura e análise da estrutura de Artigos } \\
\text { Científicos. }\end{array}$ & $\begin{array}{l}\text { Continuação da elaboração de uma } \\
\text { apresentação para comunicação oral }\end{array}$ \\
\hline Quinto dia & $\begin{array}{l}\text { Apresentação e análise da estrutura de } \\
\text { Pôsteres Científicos }\end{array}$ & $\begin{array}{l}\text { Continuação da elaboração de uma } \\
\text { apresentação para comunicação oral }\end{array}$ \\
\hline Sexto dia & $\begin{array}{l}\text { Socialização das apresentações para } \\
\text { Comunicação Oral. }\end{array}$ & \\
\hline
\end{tabular}

Fonte: Autores, 2016. 


\section{Resultados e Discussão}

O curso teve duração de 30 horas e um total de 15 participantes concluintes entre acadêmicos dos cursos de graduação em Licenciatura em Pedagogia e de Bacharel em Ciência e Tecnologia de Alimentos da UERGS. A execução do curso envolveu atividades expositivas fundamentadas nas normas que regem a elaboração de artigos, resenhas críticas, resumos simples e pôsteres científicos, além de normas para apresentação de comunicação oral. Durante cada dia do curso, apresentou-se aos alunos um tipo de gênero de texto acadêmico, dando ênfase na sua estrutura, nos elementos que o caracterizam e nas suas funções comunicativas da linguagem da comunidade acadêmica.

Nas discussões do grupo, ficou evidente que aprender a escrever como esperado na academia não é uma habilidade fácil. Tal competência necessita domínio do conteúdo, do padrão do gênero e da prática de redação. Conforme afirma Marinho (2010), é necessário superarmos a crença do domínio da língua como garantia para o domínio do gênero. Para isso, faz-se necessário o desenvolvimento de atividades de ensino-aprendizagem da escrita acadêmica de modo ativo, objetivando oferecer aos acadêmicos, que têm dificuldades de leitura e de escrita da linguagem universitária, a oportunidade de reestruturar sua escrita de redação.

Em busca de aperfeiçoar essas aptidões, foi proposto aos participantes do curso elaborar um resumo de 250 palavras e uma resenha crítica da crônica "A normose acadêmica", após esses gêneros serem trabalhados em aula. Quando em frente ao computador, os acadêmicos demonstraram dificuldade para iniciar e sintetizar as informações do texto para elaborar os seus textos. No entanto, esses obstáculos no desenvolvimento dos gêneros textuais, foram superados quando relembrados da intervenção pedagógica que havia sido desenvolvida momentos antes. Após o direcionamento, os alunos conseguiram elaborar, adequadamente, a forma estruturada do resumo e da resenha.

Os alunos também elaboraram uma apresentação padrão de comunicação oral - conforme o manual de trabalhos acadêmicos da UERGS - de tema livre, que foi socializada entre os participantes. Esse foi o gênero que apresentou maior dificuldade e tempo entre a maioria dos acadêmicos, principalmente quanto à formatação da apresentação, à delimitação do assunto e à forma de referenciar as suas fontes utilizadas no trabalho. Nessa última, evidenciou-se ser preocupante, pois alguns dos alunos demonstraram pouco conhecimento de como citar um autor ou referenciá-lo, sendo necessário, futuramente, desenvolver mais trabalhos para auxiliar na superação dessa dificuldade.

A comunicação oral e a apresentação power point, segundo Rojo e Schneuwly (2006), são dois gêneros que embora se materializem em modalidades diferentes - gráfica e fônica - não podem ser considerados como separados entre oralidade e escrita. Ao contrário, são gêneros secundários 
mutuamente constitutivos, um fazendo parte do outro de maneira determinante. A relação entre um e outro não é de semelhanças e diferenças, mas de efeito mútuo e de entrelaçamento.

No momento em que se desenrolaram as apresentações orais dos materiais elaborados pelos acadêmicos evidenciou-se dois opostos: alunos com maior domínio dos recursos de software souberam utilizar melhor suas apresentações para informar o conteúdo pesquisado e desenvolvê-lo de forma oral com coerência e clareza e, por outro lado, os estudantes que não tinham prática com a utilização de um computador realizaram apresentação precária e ineficaz para desenvolver a temática da sua apresentação. As dificuldades de apresentar a comunicação oral, por alguns participantes, foram em decorrência de ter que estar na frente de uma plateia, mesmo sendo essa os próprios colegas de curso. Uma das causas deve-se ao fato de este gênero ter uma função planejadora da fala formal pública (no trabalho, no espaço acadêmico) e exerce controle e apoio à execução desta fala, assim como apoia também a compreensão da plateia. $O$ texto dos slides esquematiza a fala e o número de slides, por sua vez, serve de controle do tempo de execução da fala (ROJO; SCHNEUWLY, 2006).

Ao final do curso, pôde-se observar uma evolução quanto ao conhecimento das estruturas que compõe cada forma de gênero acadêmico-científico. Isso se deve em virtude da intervenção mediada, que foi elaborada de forma a proporcionar aos acadêmicos um espaço-tempo favorável de aprendizagem. Dessa maneira, foi possível oferecer à turma um embasamento necessário para a elaboração de gêneros de textos acadêmicos e a autonomia para desenvolverem ideias e percepções nas suas escritas.

Para muitos acadêmicos a barreira de não saber como fazer foi desfeita, restando agora iniciar a escrever as suas futuras publicações, visto que o ato de escrever é uma atividade que requer conhecimento, esforço e vontade de aprender. Os resultados do curso confirmam que a espécie humana caracteriza-se pela diversidade e pela complexidade de suas formas de organização e de suas formas de atividades. Essas peculiaridades fazem com que se considere as ações humanas em suas dimensões sociais e discursivas. Justifica-se, pois, a linguagem humana como produções interativas associadas às atividades sociais resultantes do meio em que as atividades se desenvolvem.

Tais pressupostos estão firmados na teoria vygotskyana que defende que a cooperação entre os indivíduos é produto da interação social, e que a linguagem teria surgido por meio de uma negociação das intenções dos membros de um grupo envolvidos em uma mesma atividade. Seria na interação entre indivíduos que se realizariam ações sociais representadas pela linguagem. Nessa abordagem, assim como a atividade social pode ser enfocada sob o ângulo psicológico da ação, a atividade da linguagem também pode ser vista como ação de linguagem. Tal manifestação estaria condicionada a um emissor e se materializaria através de um gênero textual. No caso, os gêneros acadêmico/científicos que servem aos acadêmicos como forma de expressão e interação social entre seus pares. 


\section{Considerações finais}

O estudo dos gêneros textuais como ferramenta de ensino e de aprendizagem de leitura e de produção de textos apresenta-nos uma nova condição de conhecimento, no sentido de que nos serve de mediação para explorar os gêneros em sala de aula com atividades que possibilitem ao aluno agir adequadamente com a linguagem em diferentes contextos e situações. Os fundamentos tratam de questões relacionadas à aprendizagem e ao desenvolvimento das habilidades de linguagem. Sublinham que os textos são produtos da atividade humana e estão articulados às necessidades, aos interesses e às condições de funcionamento das formações sociais nas quais são produzidos. Tal embasamento é oriundo da filosofia e das ciências humanas como a psicologia, a sociologia e a semiótica (percebendo a linguagem nas dimensões discursivas e/ou textuais).

Nessa linha de pensamento, uma das contribuições dos gêneros textuais é permitir compreender que todo texto é resultado da interação entre locutores, ou seja, é produzido por alguém e se dirige a outro alguém, permitindo implicações interativas entre ambos. Assim, os estudos voltam-se não apenas para a produção do texto, mas para a sua identificação pelo leitor. Essa constatação é muito relevante no processo de ensino e no processo de aprendizagem da produção de textos, uma vez que deixa clara a relação entre o texto e a situação de comunicação. Tal processo interativo permite que os objetivos a serem alcançados estabeleçam a diferença na estrutura organizacional do texto, além de nortearem as escolhas lexicais para a produção de determinado gênero textual. Portanto, no momento da escrita no qual o aluno seleciona a linguagem e o modo de organização textual, ele passa a constituir-se autor, isto é, aquele que sabe como produzir seu discurso inserido numa determinada situação comunicativa para alguém definido (PAZ, 2006).

Por sua vez, os textos acadêmicos são de fato complicados e até muito difíceis para os acadêmicos em qualquer nível da graduação. No entanto, esses gêneros possuem características próprias para conseguirem ser universal a todos os interessados da área e, especificamente, do nosso contexto universitário. Então, fica evidente que para obtermos produções melhores devemos ler, escrever, reler e escrever continuamente, a fim de produzirmos os gêneros de textos adequados a cada situação discursiva. Consequentemente, auxiliar os acadêmicos nas atividades de leitura e de produção textual é uma forma de garantir um ensino e uma aprendizagem de qualidade com o objetivo de transformação social e conquista da cidadania.

\section{Referências}

BAKHTIN, M. Estética da Criação Verbal. São Paulo: Martins Fontes, 2006.

FIGUEIREDO, D. C.; BONINI, A. Práticas discursivas e ensino do texto acadêmico: concepções de alunos de mestrado sobre a escrita. Linguagem em (Dis)curso - LemD, Tubarão, v. 6, n. 3, p. 413446, set./dez. 2006.

FIAD, R. S. A escrita na universidade. Revista da ABRALIN, v. eletrônico, n. especial, p. 357-369. $2^{\text {a }}$ parte, 2011. 
LARROSA, J. O ensaio e a escrita acadêmica. Educação e realidade, v.18, n.2, p.101-115, 2003.

MARINHO, M. A escrita nas práticas de letramento acadêmico. RBLA, Belo Horizonte, v. 10, n. 2, p. 363-386, 2010.

PAZ, D. M. S. Produção textual. Santa Maria, RS: Ponto gráfico, 2006.

ROJO, R.; SCHNEUWLY, B. As relações oral/escrita nos gêneros orais formais e públicos: o caso da conferência acadêmica. Linguagem em (Dis)curso - LemD, Tubarão, v. 6, n. 3, p. 463-493, set./dez. 2006.

SILVA, L. N. et al. Manual de trabalhos acadêmicos e científicos da UERGS: orientações práticas à comunidade universitária da UERGS. Porto Alegre: Universidade Estadual do Rio Grande do Sul, 2013.

SOUZA, R. S. A normose acadêmica. In: NASCIMENTO, L. F. M. (Org). Lia, mas não escrevia: contos, crônicos e poesia. Porto Alegre: [S.n.], 2014. 